\title{
Parasitological Contamination of Wastewater Irrigated and Raw Manure Fertilized Vegetables in Mekelle City and Its Suburb, Tigray, Ethiopia
}

\section{Zewdneh Tomass* and Dawit Kidane}

Department of Biology, College of Natural and Computational Sciences, P.O. Box 231, Mekelle University, Mekelle, Tigray, Ethiopia (*tom_zewde@yahoo.com)

\begin{abstract}
Watering of vegetables in developing countries including Ethiopia is done using untreated wastewater and raw manure of domestic animal origin is used as fertilizer. Thus, vegetables are considered to be the principal sources of human infection with bacterial, protozoan and helminth parasites. Therefore, the objective of this study was to evaluate the rate of parasitological contamination of pre-harvest vegetables in Mekelle city and its suburban village, 'Mariam Dahan'. Pre-harvest vegetables were collected from the field during the dry season, washed using physiological saline solution, allowed to sediment overnight, centrifuged and examined microscopically for infective stages of intestinal parasites. Out of the vegetable samples examined, 32.41\% in Mekelle city and 30.49\% in 'Mariam Dahan', contained at least one parasitic contaminant. Strongyloides stercoralis was most encountered parasitic contaminant in the study areas, followed by, Taenia and Entamoeba spp. Highest rate of parasitic contamination was detected on Swiss chard, that was 45.5 and $41.67 \%$ in Mekelle city and 'Mariam Dahan', respectively. Occurrence of infective stages of intestinal parasites on wastewater- irrigated vegetables may pose public health hazards to farming communities in the study areas. Therefore, evaluation and surveillance of parasitological quality of vegetables is crucial in an attempt to control vegetable-transmitted parasitic infections.
\end{abstract}

Key words: Untreated wastewater, Raw manure, Pre-harvest Vegetables, Parasitological contamination, Tigray, Ethiopia

\section{INTRODUCTION}

Increasing water scarcity in dry climate regions with agriculture based economy forces people to use untreated wastewater for irrigation of crops. Practice of using untreated municipal wastewater for irrigation, raw manure as fertilizer and habit of eating vegetables raw or undercooked are reported to result in risk of infection with intestinal parasites in developing countries (Blumenthal, 2000). Infection with vegetable-transmitted parasites and pathogenic bacteria can occur due to occupational exposure or through consumption of vegetables that are contaminated with human or animal excreta without proper washing and disinfection (WHO, 2006; Beuchat, 1998). Unhygienic sewage disposal and absence of its treatment facilities pose potential health hazards through contaminating irrigated food crops with parasites in urban and suburban areas of African countries including Ethiopia (Srikanth and Naik, 2004a; Damen, et al., 2007; Nyarango et al., 2008; Weldesilassie et al., 2009). 
Vegetables are reported to harbor intestinal parasites such as Ascaris lumbricoides, Taenia spp, Fasciola hepatica, Hymenolepis nana, Echinococcus spp, Trichuris spp, Enterobius vermicularis, Trichostrongylus spp, Toxocara.spp, Strongyloides stercoralis, Giardia lamblia, Entamoeba spp, Iodamoeba butschlii, Blastocystis hominis and Cryptosporidium parvum (Gharavi et al., 2002; Gupta et al., 2009; Abougrain et al., 2009; Uga et al., 2009). The resistant nature of infective stages of the aforementioned parasites such as eggs, cysts or oocysts to adverse temperatures, desiccation, natural irradiation, chemicals and commonly used disinfectants results in high prevalence of vegetable-transmitted parasites in developing countries (Beuchat, 1998). On the other hand, living under immunocompromized situation mainly due to HIV/AIDS exposes some percentage of the population across the world to opportunistic vegetable-transmitted parasites such as Cryptosporidium spp (Esrey et al., 1998).

Several studies documented prevalence of intestinal parasites in different parts of Ethiopia including Tigray region through microscopic examination of stool samples collected from suspected human population (Legesse and Erko, 2004; Tadesse, 2005; Dejenie and Petros, 2009). However, research endeavors to detect parasites from environmental sources such as vegetables are scarce in Ethiopia (ROSA, 2009). Therefore, the objective of this study was to determine the rate of parasitological contamination of vegetables associated with the use of municipal wastewater for irrigation and raw manure as fertilizer on pre-harvest vegetables in Mekelle city and a suburban village, 'Mariam Dahan', located at its Northern edge.

\section{METHODOLOGY}

\subsection{Study Areas}

Mekelle is the capital city of Tigray Region located $780 \mathrm{~km}$ north of Addis Ababa, the capital city of Ethiopia (Fig. 1). Its geographic location is $13^{\circ} 32^{\prime} \mathrm{N}$ and $39^{\circ} 33^{\prime} \mathrm{E}$. It has an average altitude of 2200 meters above sea level with a mean minimum, mean maximum and mean average monthly temperatures of 8.7, 26.8 and $17.6^{\circ} \mathrm{C}$, respectively (Kibrom, 2005). Amount of rainfall is variable in Mekelle; on average about $600 \mathrm{~mm}$, and more than $70 \%$ of it falls between July and August, followed by long dry season (Kibrom, 2005). Mekelle has an estimated total population of 215,546 (CSA, 2008). The municipal wastewater of Mekelle flows through the main canal running from 'Kebelle 18' ('Hadinet') area at the south east of the city, to industrial zone area at its northern periphery (Personal observation during filed visit). 'Mariam Dahan' is 
located at about 3-4 km from the center towards northern edge of Mekelle city (Fig.1). Farmers living along the length of the wastewater drainage canal in Mekelle city and adjacent to 'Elala' stream in 'Mariam Dahan' village cultivate vegetables for both household consumption and income generation.

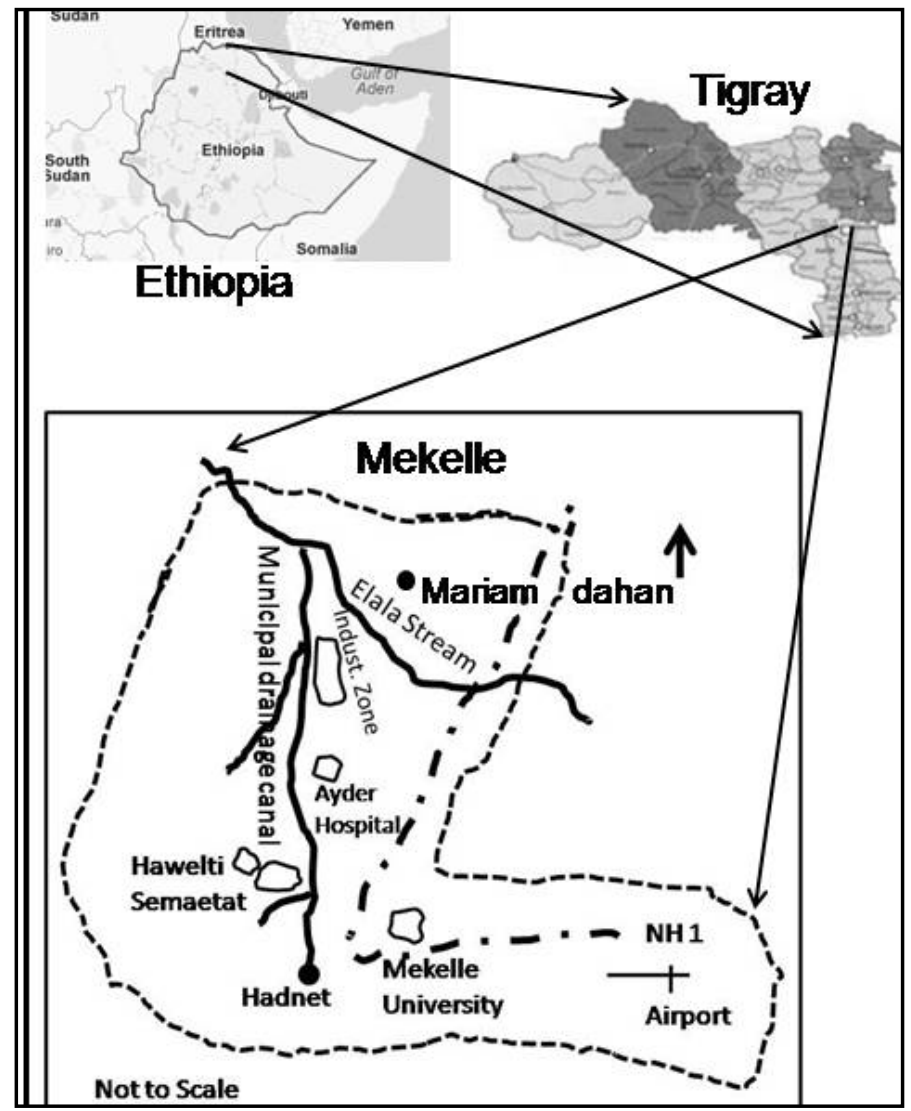

Figure 1. Map of the study area.

\subsection{Study Design}

The study areas were selected based on personal observation of practice of using municipal wastewater in Mekelle city and 'Elala' stream in 'Mariam Dahan' as sources of water for irrigation; practice of outside defecation along the wastewater drainage canals in Mekelle city and 'Elala' stream in 'Mariam Dahan' as well as using raw manure of domestic animal origin and sewage as fertilizers on vegetable farms. All vegetable farms along the length of the municipal wastewater drainage canal in Mekelle city and all the vegetable farms adjacent to 'Elala' stream in 'Mariam Dahan' village (that are at close proximity to Mekelle city) were selected for the study. In both of the study areas, farms at a horizontal distance of 10-30 meters 
away towards the left or right of the irrigation source waters were used for collection of vegetable samples. The two study sites were selected to see if there is any difference in parasitic contamination of vegetables taking distance into account. Close-ended interview questionnaire were first prepared in English and then translated into the local language, Tigrigna, for collection of data on demographic information of farmers and their agronomic practices.

\subsection{Survey for Demographic Information and Agronomic Practices}

Interviews were administered to all farmers involved in the study. Questionnaire contained variables such as, demographic information, irrigation schedule and types of fertilizers used.

\subsection{Collection of Samples Vegetables}

Samples of pre-harvest leafy, fruit and root vegetables were collected from a total of 39 small scale farms, located along the wastewater drainage canal in Mekelle city and 'Elala' stream in 'Mariam Dahan' village during the dry season, January-May, 2011. Vegetable samples were collected in triplicates from each farm using separate sterile plastic bags and transported on the same day to the Parasitology Laboratory of the Department of Biology, Mekelle University.

\subsection{Detection of Helminth Eggs and Protozoan Cysts}

In the laboratory, a sample of $100 \mathrm{~g}$ of each fresh vegetable was chopped into small pieces and put into a clean beaker containing physiological saline solution $(0.85 \% \mathrm{NaCl})$, enough to wash the sample vegetable. After removing fragments of the vegetable sample from the washing saline using clean forceps, it was kept overnight for sedimentation. After overnight sedimentation, the top layer of the washing saline was carefully discarded and $5 \mathrm{ml}$ of the sediment was centrifuged at 2000 rotations per minute. After discarding the supernatant, the residue was mounted on slides, stained in Lugol's iodine solution and examined using light microscopy to screen the samples for infective stages of intestinal parasites such as helminth eggs, larvae and protozoan cysts ( Abougrain et al., 2009; Uga et al., 2009). To increase the chance of parasite detection, two slides were prepared for each vegetable sample. 


\subsection{Statistical Analysis}

Comparison among different vegetables regarding positivity for parasitic contaminants was performed using the Chi-squares test (Das, 2009). Independent samples t-test of the SPSS for windows, version 15.5 was used to test difference in positivity of vegetables for parasites between Mekelle city and 'Mariam Dahan' village and $P$-values $<0.05$ were considered significantly different.

\section{RESULTS}

\subsection{Demographic Information and Agronomic Practices}

A total of 41 household heads with ages ranging from 20-74 years were found to be engaged in vegetable cultivation in both Mekelle city and 'Mariam Dahan'. Out of these, 39 (95\%) were males and 2(5\%) were females. Vegetable farming is a fulltime occupation for about 27 (66\%) of the farmers. Farmers had frequency of irrigating their vegetables ranging from once a week 26(63.41\%) to twice a week 15(36.59\%) with municipal wastewater in Mekelle city and Elala stream, in ‘Mariam Dahan’ village (Table. 1).

Out of 108 samples vegetables collected from 24 small farms along the wastewater drainage canal in Mekelle city, 35(32.41\%) were found to be positive for at least one parasitic contaminant. The positivity for parasites is not similar among the vegetables in Mekelle city $(P<$ 0.05) (Table. 2).

Out of 82 sample vegetables collected from 15 small farms along 'Elala' stream in 'Mariam Dahan' village, 25 (30.49\%) were found to be contaminated with at least one parasitic contaminant. The positivity for parasites is similar among the vegetables in 'Mariam Dahan' ( $\mathrm{P}$ > 0.05) (Table 3).

The positivity of vegetables for parasitic contaminants between Mekelle and 'Mariam Dahan'was not significantly different $(P=0.893)$.

In Mekelle, Strongyloides stercoralis was the most common parasitic contaminant detected in most of the vegetables examined 28 (63. 63\%) followed by Taenia and Entamoeba spp however, the difference was not statistically significant $(P>0.05)$ (Table 4).

In 'Mariam Dahan' village, the distribution of parasites among the vegetables is different with Strongyloides stercoralis being the most frequent contaminat $(P<0.05)$ (Table 5). 
The distribution of parasites on vegetables between Mekelle and 'Mariam Dahan' was not significantly different $(P=0.529)$.

Table 1. Demographic information and agronomic practices of farmers engaged in vegetable cultivation in Mekelle city and 'Mariam Dahan' village, Tigray, northern Ethiopia (January-May, 2011).

\begin{tabular}{|ll|}
\hline Variables & \multicolumn{1}{c|}{ No (\%) of farmers encountered } \\
\hline Age range in years & $01(2.44)$ \\
\hline $20-24$ & $06(14.63)$ \\
\hline $25-29$ & $03(7.32)$ \\
\hline $30-34$ & $01(2.44)$ \\
\hline $35-39$ & $07(17.07)$ \\
\hline $40-44$ & $11(26.83)$ \\
\hline $45-49$ & $03(7.32)$ \\
\hline $50-54$ & $03(7.32)$ \\
\hline $55-59$ & $01(2.44)$ \\
\hline $60-64$ & $03(7.32)$ \\
\hline $65-69$ & $02(4.88)$ \\
\hline $70-74$ & \\
\hline & $39(95.12)$ \\
\hline Male & $2(4.88)$ \\
\hline Female & $14(34.15)$ \\
\hline Vegetable cultivation as an occupation & $27(65.85)$ \\
\hline Par time & \\
\hline Full time & $26(63.41)$ \\
\hline Frequency of irrigation & $15(36.59)$ \\
\hline Once/week & $13(31.71)$ \\
\hline Twice/week & $15(36.58)$ \\
\hline Type of fertilizer used & $10(24.39)$ \\
\hline Household manure & $03(7.32)$ \\
\hline Chemical fertilizer & \\
\hline Compost & \\
\hline Sewage & \\
\hline
\end{tabular}

Table 2. Pre-harvest parasitic contamination of vegetables in Mekelle City, Tigray, northern Ethiopia (January-May, 2011).

\begin{tabular}{|lll|}
\hline Vegetable type & Examined (No.) & Positive No. (\%) \\
\hline Lettuce & 21 & $6(28.57)$ \\
\hline Swiss chard & 59 & $18(30.51)$ \\
\hline Onion & 10 & $5(50)$ \\
\hline Cabbage & 15 & $5(33.33)$ \\
\hline Tomato & 3 & $1(33.33)$ \\
\hline Chi-Square $=8.29, P<0.05$ & \\
\hline
\end{tabular}


Table 3. Pre-harvest parasitic contamination of vegetables in 'Mariam Dahan' village, Tigray, northern Ethiopia (January-May, 2011).

\begin{tabular}{|lll|}
\hline Vegetable type & Examined (No.) & Positive No. (\%) \\
\hline Swiss chard & 56 & $11(19.64)$ \\
\hline Onion & 19 & $12(63.16)$ \\
\hline Cabbage & 4 & $1(25)$ \\
\hline Tomato & 3 & $1(33.33)$ \\
\hline Chi-square $=32.07, P>0.05$ & \\
\hline
\end{tabular}

Table 4. Distribution of intestinal parasites on vegetables collected from wastewater irrigated farms in Mekelle city.

\begin{tabular}{|lllllll|}
\hline Parasites & \multicolumn{7}{c|}{ Names of vegetables } \\
\cline { 2 - 8 } & Lettuce & Swiss chard & Onion & Cabbage & Tomato & Total (\%) \\
\hline $\begin{array}{l}\text { Strongyloides } \\
\text { stercoralis }\end{array}$ & 7 & 11 & 9 & 1 & 0 & 28 (63.63) \\
\hline Taenia spp & 0 & 4 & 0 & 4 & 0 & $8(18.18)$ \\
\hline Entamoeba spp & 1 & 5 & 0 & 1 & 1 & $8(18.18)$ \\
\hline
\end{tabular}

Table 5. Distribution of intestinal parasites on vegetables collected from 'Elala' stream-irrigated farms in 'Mariam Dahan' village.

\begin{tabular}{|llllll|}
\hline \multirow{2}{*}{ Parasites } & \multicolumn{5}{c|}{ Names of vegetables } \\
\cline { 2 - 6 } & Swiss chard & Onion & Cabbage & Tomato & Total (\%) \\
\hline $\begin{array}{l}\text { Strongyloides } \\
\text { stercoralis }\end{array}$ & 8 & 12 & 1 & 1 & $22(91.67)$ \\
\hline Taenia spp & 2 & 0 & 0 & 0 & $2(8.33)$ \\
\hline Entamoeba spp & 0 & 0 & 0 & 0 & $0(0)$ \\
\hline
\end{tabular}

\section{DISCUSSION}

About 66\% of the farmers in Mekelle city and 'Mariam Dahan' village were engaged in vegetable cultivation as a fulltime occupation; such engagement of farmers in vegetable cultivation in the study areas may be attributed to high demand of the products in the nearby markets. More than $60 \%$ of the farmers in the study areas claimed to irrigate their vegetables once a week. During our field visit farmers have been observed to take out wastewater from city drainage canal and 'Elala' stream in Mekelle city and 'Mariam Dahan' village, respectively, using motor pumps; then the water is flooded through channels to the vegetables probably causing potential risk of attachment of parasitic contaminants on upper as well as to lower surfaces of the vegetables. In the study areas, about $7 \%$ of the farmers claimed to use sewage as 
fertilizer; this has been substantiated by our personal observation of sanitary vehicles inundating sewage on vegetables based on farmers' request.

In the present study parasite positivity among vegetables was different in Mekelle city $(P<$ 0.05); this is may be due to the fact that different sections of the wastewater drainage canal in Mekelle city receive different load of fecal contamination although not quantified. For instance, the undersides of bridges over the wastewater drainage canal behind Abraha Kastel Hotel and adjacent to Ayder Hospital are highly contaminated with human defecation. During field visit it was also possible to observe promiscuous human defecation at the section of the wastewater canal in the vicinity of chicken market in 'Kebele'eleven. On the other hand, a section of the water drainage canal at the part of the city locally known as 'Grebtsedo' is contaminated with liquid waste discharged from the slaughter house close to it. Therefore, the difference among vegetables for their positivity for parasites in Mekelle city might be emanated from the difference in fecal contamination load at different sections of the drainage canal.

Furthermore, this study revealed the positivity for parasites among different vegetables to be similar in 'Mariam Dahan' village $(P>0.05)$; this might be because there is no difference in fecal contamination load at the different sections of 'Elala' stream surveyed. In 'Marim Dahan' village the major source of fecal contamination to 'Elala' stream was observed to be promiscuous human defecation using vegetations at the banks of the stream as privacy cover; however, the fecal materials were not quantified. Therefore, the absence of sectional difference in fecal contamination load at the portions of the stream surveyed might have contributed for similar positivity for parasites among the vegetables.

On the other hand, there was no significant difference in positivity of vegetables for parasites in Mekelle city and 'Mariam Dahan' village $(P=0.893)$; the reason for this might be the fact that the municipal wastewater which runs towards the north joins 'Elala' stream that flows from east to west at the northern periphery of Mekelle city. This may again result in mixing of the fecal contaminants contained in both of the water bodies causing similarity of vegetables for parasite positivity between Mekelle city and 'Mariam Dahan’ village.

This study assessed the health hazards of using wastewater and raw manure/sewage in Mekelle city and its northern edge suburban village, 'Mariam Dahan', for vegetable production through detecting intestinal parasites from pre-harvest vegetables. Similarly Srikanth and Naik, (2004a) 
reported the health hazards of agricultural reuse of untreated wastewater through detection of Giardia spp and fecal coliforms from pre-harvest vegetables in suburbs of Asmara, Eritrea. Weldesilassie et al. (2010) surveyed prevalence of intestinal illness among households in relation to the use of wastewater for vegetable production in peri-urban areas of Addis Ababa, Ethiopia; however, these authors did not carry out microscopic detection of intestinal parasites from wastewater grown vegetables. Helminth parasites identified from pre-harvest vegetables in the present study include larvae of Strongyloides stercoralis and eggs of Taenia spp. A study on parasitological quality pre-harvest vegetables in Arba Minch, southern Ethiopia, reported several helminth parasites including Ascaris lumbricoides, Hymenolepis nana, Fasciola hepatica, Enterobius vermicularies and Hook worm (ROSA, 2009). The reason for the recovery of only few helminth parasites in the present study as compared to the study in Arba Minch, might be reattributed to the method used to remove supernatant from sedimented sample washout; which was by direct decantation in present study but by a suction pump of the Bailenger method (Ayres and Mara, 1996) in the study in Arba Minch. On the other hand, Entamoeba spp was the only protozoan parasite detected in the present study. A study in Asmara and its suburbs, Eritrea, reported a protozoan parasite, Giardia spp, from wastewater irrigated-vegetables (Srikanth and Naik, 2004b). Generally, sensitivities of methods used to extract infective stages of intestinal parasites and the underlining epidemiological difference in farming communities may contribute for the occurrence of different kinds of helminth or protozoan parasites on wastewater irrigated vegetables in different localities.

This study identified limited types of parasitic contaminants on the vegetables examined. The reason for the occurrence of limited types of parasites in the present study might be because during pre-harvest period vegetables are only exposed to production related sources of parasitic contaminants associated with practices of using untreated wastewater for irrigation and sewage/ raw manure of domestic animal origin as fertilizer. On the other hand, diverse occurrence of parasitic contaminants on post-harvest vegetables is attributed to unhygienic handling during transportation, marketing as well as preparations before consumption (Beuchat, 1998; Damen et al., 2007).

In this study Strongyloides stercoralis was found to be the most frequent parasitic contaminant; however, the difference was not statistically significant in Mekelle city. It occurred in higher rates on onion, followed by Swiss chard and lettuce. S. stercoralis is a nematode parasite which 
attains its larval development inside soil (Cox, 1993). Root vegetables such as onion are reported to be continuously exposed to parasitic contaminants in the soil (Larkin et al., 1978). On the other hand, in the present study all parts of Swiss chard and lettuce including the bottom (close to soil) stalks have been washed for parasite extraction which might be the reason for the occurrence of S. stercoralis on these leafy vegetables. During our field visit Swiss chard and lettuce grown on wastewater-irrigated or sewage-fertilized plots were observed to have dense foliage and abnormally long and broad leaves (though not measured) which might have increased their contact area to the soil rendering contamination with S. stercoralis.

Strongloides stercolaris initiates infection to farming community working barefooted on a contaminated soil through skins penetration. On the other hand, infection with Taenia and Entamoeba spp can be initiated through ingestion of vegetables contaminated with the parasites (Cox, 1993). The overall frequency of parasites on tomatoes was very low this may be due to few samples obtained during field survey. In addition, smooth surface morphology and narrow contact area of tomatoes might have reduced parasite attachment microhabitats on its surface; such speculations have also been made by Idrissa et al. (2010) in Moroco.

\section{CONCLUSION}

The present study identified parasitic contaminants on pre-harvest vegetables associated with the use of wastewater, raw manure or sewage for vegetable production; suggesting the fact that the parasites identified may pose occupational risk of infection to the farming communities. Therefore, awareness creation on the health hazards of using wastewater, raw manures or sewage for vegetable production, construction of fencing to discourage human defecation under bridges, construction of enough public toilets at areas where people gather in large numbers as well as keeping the overall environmental hygiene are highly recommended to avoid contamination of pre-harvest vegetables with intestinal parasites in the study areas.

\section{ACKNOWLEDGEMENT}

This study received financial support from the College of Natural and Computational Sciences (CNCS), Mekelle University. Vegetable samples were obtained from small scale farmers of Mekelle city and 'Mariam Dahan’ village. We are grateful to Dr Tadesse Dejenie and Mr Negash Aregay for logistic support and preliminary information about the study sites, respectively. Dr. 
Ekwal Imam, Mr. Getachew Gidey, Mr.Gebru Equar, and W/ro Atkilt Berihun are acknowledged for their help during field sample collection. We would like to thank W/t Miheret Hadgu for her unreserved assistance in processing sample vegetables for examination. Mr. Atsbaha Gebrekidan is highly acknowledged for microscopic examination and detection of infective stages of intestinal parasites from the sample vegetables.

\section{REFERENCES}

Abougrain, A. K., Nahaisi, M. H., Madi, N. S.,Saied, M. M \& Ghenghesh, K. S. 2009. Parasitological contamination in salad vegetables in Tripoli-Libya. Food Control, doi:10.1016/j.foodcont.2009.11.005

ROSA, 2009. A preliminary survey of the microbiological and parasitological quality of some locally produced and marketed vegetables done as part of the ROSA research activity in Arba Minch, Ethiopia, 43-44pp.

Beuchat, L. R. 1998. Surface Decontamination of Fruits and Vegetables Eaten Raw. A Review Document, WHO/FSF/FOS/98.2 .

Blumenthal, U., Peasey, A., Ruiz-Palacios, G \& Mara, D. 2000. Guidelines for waste water reuse in agriculture and aquaculture: recommended revisions based on new research evidence.WEDC, Loughborough University, UK, 42p.

Central Statistical Agency (CSA). 2008. Census 2007, Addis Ababa, Ethiopia.

Cox, F.E.G. 1993. Modern Parasitology: A text book of Parasitology, Blackwell Science Ltd, $2^{\text {nd }}$ Edition, Australia, 46-47pp.

Damen, J.G., Banwat, E. B., Egah, D. Z \& Allanana, J.A. 2007. Parasitic Contamination of Vegetables in Jos, Nigeria. Annals of African Medicine, 3: 115 - 118.

Das, P. N. 2009. Instant medical Biostatistics. Ane Books Pvt Ltd, New Delhi, 170p.

Dejenie, T \& Petros, B. 2009. Irrigation Practices and Intestinal Helminth Infections in Southern and Central Zones of Tigray. Ethiopian Journal of Health Development, 23:48-56.

Esrey, S.A., Gough, J., Rapaport, D., Sawyer, R., Simpson-Hébert, M., Vargas, J \& Winblad, U. 1998. Ecological sanitation. Sida, Stockholm, 14p.

Gharavi, M. J., Jahani, M. R \& Rokni, M. B. 2002. Parasitic contamination of vegetables from farms and markets in Tehran. Iranian Journal of Public Health, 13:83-86 
Gupta, N., Khan, D.K \& Santra, S.C. 2009. Prevalence of intestinal helminth eggs on vegetables grown in wastewater-irrigated areas of Titagarh, West Bengal, India. Food Control, 20: 942-945.

Idrissa, S. Belghyti, D. Kharrim, K.E \& Yoro, C. 2010. Parasitic Contamination of the Mint and Turnip Irrigated by untreated wastewater in Sidi Yahia Gharb (Morocco). BALWOIS 2010 Conference, Ohrid, Republic of Macedonia.

Kibrom, G. 2005.Investigation into engineering properties of Mekele soils with an emphasis on expansive soils. MSc Thesis, Addis Abeba University, Ethiopia.

Larkin, E. P., Tierney, J. T., Lovett, J. Van Donsel, D., Francis, D. W \& Jackson, G. J. L. 1978. Land application of sewage wastes: potential for contamination of food stuffs and agricultural soils by viruses, bacterial pathogens and parasites. In: H. L.Mc Kim (eds). State of knowledge in land treatment of wastewater. Hanover, NH: US Army Corps of Engineers, Crrel, 215-223 pp.

Legesse, M \& Erko, B. 2004. Prevalence of intestinal parasites among schoolchildren in a rural area close to the southeast of Lake Langano. Ethiopian Journal of Health Development, 18: $116-120$.

Ayres, R. M \& Mara, D. D. 1996. Analysis of wastewater for use in agriculture -a laboratory manual of parasitological and bacteriological techniques. WHO, Geneva, 7-11 pp.

Nyarango, R.M., Aloo, P.A., Kabiru, E.W \& Nyanchongi, B. O. 2008. The risk of pathogenic intestinal parasite infections in Kisii Municipality, Kenya. BMC Public Health, 8:237.

Srikanth, R \& Naik, D. 2004a. Prevalence of Giardiasis due to wastewater reuse for agriculture in the suburbs of Asmara City, Eritrea. International Journal of Environmental Health Research, 14: 43-52.

Srikanth, R \& Naik, D. 2004b. Health effects of wastewater reuse for agriculture in the suburbs of Asmara City, Eritrea. International Journal of Occupational and Environmental Health, 10: 284-288.

Tadesse, G. 2005. The prevalence of intestinal helminthic infections and associated risk factors among school children in Babile town, eastern Ethiopia. Ethiopian Journal of Health Development, 19:140-147. 
Uga, S., Hoa, N.T.V., Noda, S., Moji, K., Cong, L., Yaoki, S.K., Rai \& Fujimaki, Y. 2009. Parasite egg contamination of vegetables from a suburban market in Hanoi, Vietnam. Nepal Medical College Journal, 11:75-78.

Weldesilassie, A. B., Frör, O., Boelee, E \& Dabbert, S. 2009. The economic value of improved wastewater irrigation: A contingent valuation study in Addis Ababa, Ethiopia. Journal of Agricultural and Resource Economics, 34: 428-44.

Weldesilassie, A. B., Boelee, E., Drechsel, P \& Dabbert, S. 2010. Wastewater use in crop production in peri-urban areas of Addis Ababa: impacts on health in farm households. Environment and Development Economics, Cambridge University Press, 1-25, doi:10.1017/S1355770X1000029X.

WHO, 2006. WHO guide lines for the safe use of wastewater, excreta and greywater: Wastewater use in agriculture. Volume II, Worlad Helath Organization, France, 22p. 